\title{
A multi-stratal perspective on circumstantial meaning
}

\author{
Shoshana Dreyfus ${ }^{\mathrm{D}}{ }^{\mathrm{a}}$ and Jing $\mathrm{Hao}^{\mathrm{b}}$

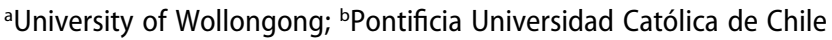

\begin{abstract}
This paper provides a "broader" understanding of what is previously known from a grammatical perspective as "circumstantial meaning" or circumstantiation. This "broader" perspective takes into account more abstract meanings beyond grammar, considering both field (at the register stratum) and discourse semantics, in addition to lexicogrammar. The paper shows how the lexicogrammar alone is not able to adequately account for the meaning potential of "circumstantial meaning", and how by examining this region of meaning from three strata, a fuller account of circumstantial meaning is made possible. A richer account of circumstantial meaning is necessary because, while circumstances may be considered structurally peripheral, earlier explorations of circumstantial meaning show that this area of meaning often makes important contributions to the register of any given text and to the building of disciplinary knowledge. This exploration is demonstrated through two texts: a student's high scoring piece of creative writing from the subject of English in the final year of schooling and a synopsis of a history book on the Chinese fishing industry in colonial Australia. These texts reveal the significantly different ways in which circumstantial meanings are used in different subject areas - i.e., to contribute to setting up an "ambience" in literary texts and to developing knowledge in history.
\end{abstract}

\section{ARTICLE HISTORY}

Received 29 May 2019

Accepted 20 January 2020

\section{KEYWORDS}

Circumstantial meaning; register stratum; discourse semantics; lexicogrammar; systemic functional linguistics

\section{Background}

Halliday's systemic functional linguistic theory describing meaning-making in language has had a significant impact on the field of linguistics around the world. In particular, the grammatical resources of the system of TRANSITIVITY from the ideational metafunction have been crucial for enabling linguists to examine how our experiences in and of the world are both construed and constructed through language and text. From a grammatical perspective, our experiences can be construed through three key clausal constituents within the TRANSITIVITY system: Processes $^{1}-$ as realised by the verbal group in a clause; Participants - who or what are participating in the process, and typically realised by nominal groups; and Circumstances - which describe when, where, how, why, etc., the actions of the clause take place, most typically realised by prepositional phrases and adverbials. Among these, the Process and Participant make up an "experiential centre" of the clause and Circumstances are said to augment the experiential centre temporally, spatially, causally, and so on (Halliday and Matthiessen 2014, 221). As an 
augmenting element, Circumstances are "almost always optional" and thus seen as more "peripheral" in the clause (Halliday and Matthiessen 2014, 221). In addition to Circumstances at the clause rank, there are also other "circumstantial" elements that are available for construing the "when, where, how, why etc" of our experience. Halliday (1985), Halliday and Matthiessen (2014) and Martin (1992) all point to the way in which different grammatical choices at different ranks make similar "circumstantial" meanings. Dreyfus and Bennett (2017), who were interested in understanding the work that different grammatical "circumstantial" choices do in history research articles, offered a systematic study of the different grammatical realisations of circumstantial meaning. As illustrated in the examples below in Tables 1, 2, 3 \& 4, different lexicogrammatical structures, including Circumstances, Attributes, Qualifiers, and hypotactic clauses, can make similar spatial meanings at a more abstract, "higher" level.

Dreyfus and Bennett's comprehensive survey of the range of grammatical realisations of "circumstantial" meanings demonstrates that in order to account for the realisation of circumstantial meaning at a "higher level", the full range of grammatical realisations of circumstantial meaning need to be taken into account, not just Circumstances at the clause rank. This is because, as we will show in this paper, circumstantial meanings participate in the building of disciplinary knowledge of whole fields, and thus being able to account for the way they do this enables a fuller understanding of the way knowledge is construed in different fields.

Table 1. Circumstances realising "circumstantial meaning" (place).

\begin{tabular}{llll}
\hline There & \multicolumn{1}{c}{ is } & some milk & in the fridge \\
\hline & Process: existential & Existent & Circumstance: location place \\
\hline
\end{tabular}

Table 2. Participant (attribute) realising "circumstantial meaning" (place).

\begin{tabular}{lll}
\hline The milk & \multicolumn{1}{c}{ is } & in the fridge \\
\hline Carrier & Process: relational & Attribute \\
\hline
\end{tabular}

Table 3. Qualifier in a nominal group realising "circumstantial meaning" (place).

\begin{tabular}{llllc}
\hline The & milk & in the fridge & is & old \\
\hline $\begin{array}{l}\text { Carrier } \\
\text { nominal group } \\
\text { Deictic }\end{array}$ & & & Process: relational & Attribute \\
\hline
\end{tabular}

Table 4. A hypotactic clause realising "circumstantial meaning" (place) (example adapted from Halliday and Matthiessen 2014, 482).

\begin{tabular}{lc}
\hline Wherever you keep the milk, & it will eventually go sour. \\
\hline$\beta$ & $a$ \\
\hline
\end{tabular}


Dreyfus and Jones $(2008,2011)$ also explore "higher" level circumstantial meaning, focusing particularly on "place". In their study, they not only posit the importance of considering circumstantial meanings of "place" "beyond" the clause, but they also propose a categorisation of different kinds of place, taking into consideration meanings made through diverse grammatical realisations. As shown in Figure 1, in the development of first a cline and then a "fan" of place, Dreyfus and Jones map how types of place change according to the life trajectory: in the early childhood picture book texts in their study, places tended to be more concrete, pertaining to physical locations; however, as the texts move further along the path through education (both primary and secondary school), the places become more diverse and are seen to be up the more "abstract" end of the cline and fan. The abstract end includes lexical metaphors (e.g., in the valley of despair), grammatical metaphors (e.g., into physical violence) and semiotic abstractions (Martin 1997) (e.g., in his evidence).

Dreyfus \& Jones' study reveals the wide range of meaning potential of "circumstantial meaning" at a "higher" level beyond the lexicogrammar, but at the same time, several questions were left unanswered. First, it is unclear where the "higher" level meaning is situated - i.e., whether it is realised in the discourse patterns of texts, that is, as discourse semantic meanings (Martin 1992), or whether the "higher" level meaning concerns the different social contexts including disciplinary knowledges in which texts are found or are part of. Many categories of "place" in Figure 1 seem to be motivated by our social activities in different fields - i.e., socio-cultural, occupational, physiological, etc. However, connecting these "field types" directly with grammatical choices overlooks the level in between that is, the patterns of meanings that are organised in a text (rather than a clause). One consequence of this oversight is associated with the relatively more "abstract" categories at the top end of the cline in Figure 1. The metaphorical meanings, treated as a kind of "abstraction" there, include both grammatical metaphors and lexical metaphors. Grammatical and lexical metaphors are both concerned with the re-mapping (i.e., not

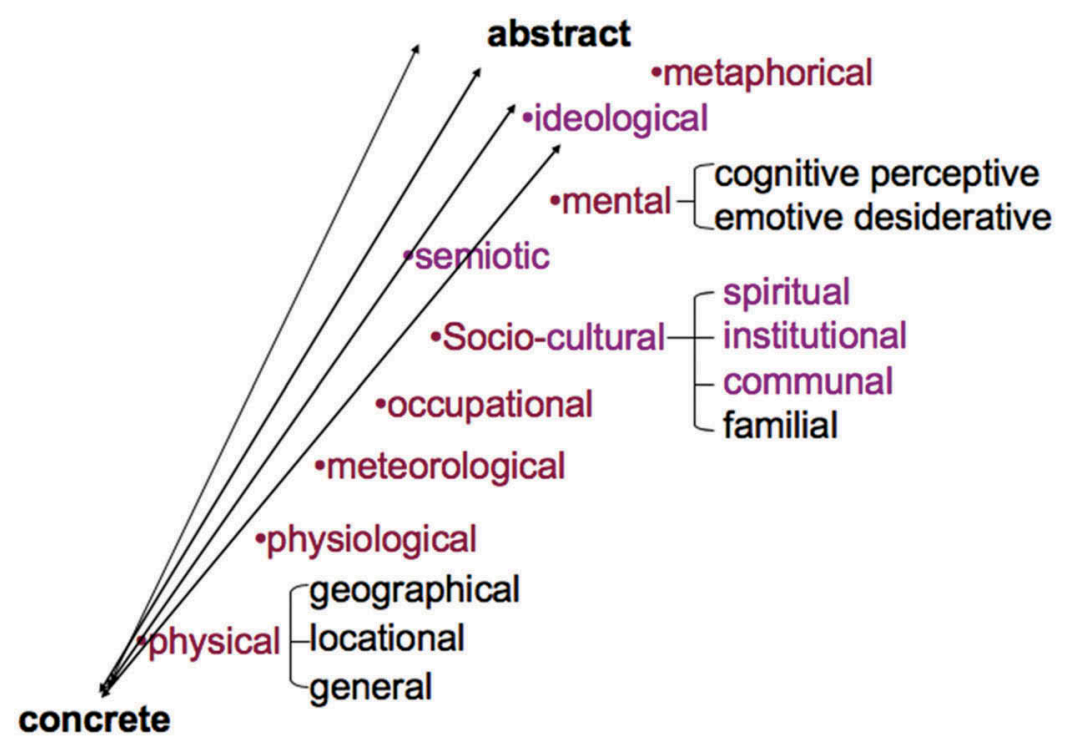

Figure 1. Dreyfus and Jones (2011) fan of place. 
the typical mapping) of meanings between different levels (Halliday 1985; Martin 2008, this volume). Grammatical metaphor is particularly concerned with the remapping between discourse semantics and lexicogrammar (e.g., the same meaning made by a clause - his office is disorganised - can be remapped onto a nominal group the disorganisation of his office) (Martin 2008; Hao 2018); whereas, as Martin (this volume) shows, lexical metaphors require the consideration of meanings across three strata: that is, across field, discourse semantics, and lexicogrammar (e.g., the metaphor "life is a journey" maps different field activities - "living a life" and "going on a trip" - and thus different language resources for construing these activities onto one another). To fully understand circumstantial meanings, the associated choices of meanings at different strata need to be further sorted out, and that is what this paper aims to achieve.

A recent set of studies on academic knowledge building has developed our understanding of stratified language and context from an SFL perspective and has rearticulated how meanings are organised at both the stratum of field (Doran and Martin forthcoming) and at the stratum of discourse semantics (Hao forthcoming a, forthcoming b, 2015, 2018). These emerging developments of stratification provide us with a useful way of beginning to sort out the "circumstantial" meanings of concern here. Figure 2 below is a visual representation of how stratified language and context are related from an SFL perspective.

Informed by the model of stratified language and context, we take field as a point of departure and examine circumstantial meanings across the three strata of field (at the register stratum), discourse semantics and lexicogrammar. As we will show, this point of departure has significant implications for understanding which circumstantial meanings are at stake in different disciplinary fields and how these are realised across the different strata. The emerging frameworks of field and discourse semantics will be introduced at different steps of the analysis in the following sections.

We begin the exploration of circumstantial meanings with a focus on the "spatial and temporal" types of meaning, because along with manner, "spatial and temporal" meanings are the most common types found in texts from a variety of contexts (Matthiessen 1998) and thus the findings potentially provide generalisable patterns across contexts.

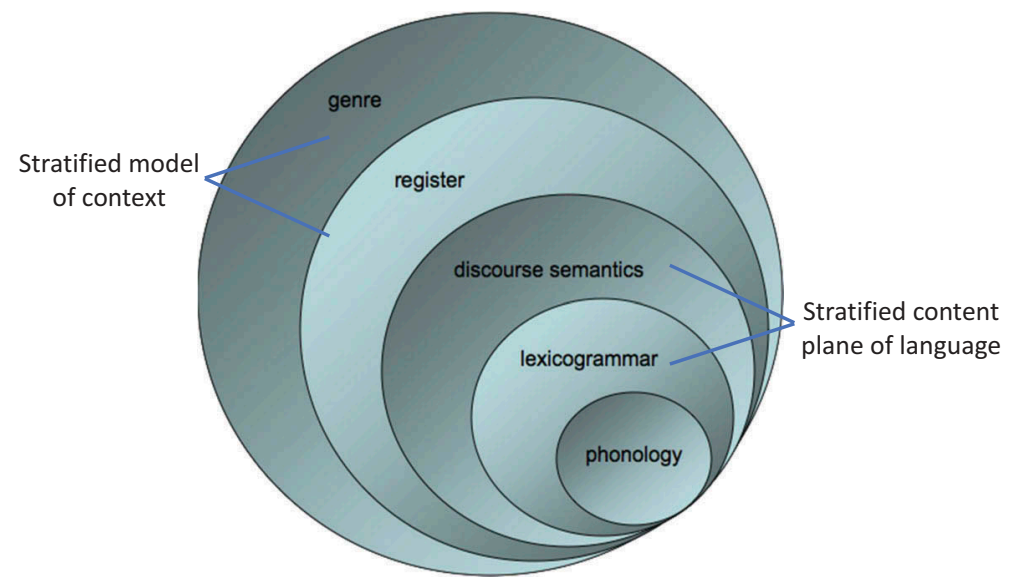

Figure 2. Stratified context and language planes from an SFL perspective. 


\section{Data}

Two texts were used for this preliminary exploration. These were selected from two different disciplinary knowledges - i.e., English and history (see Appendix). Both texts recount events from the past, with the history organised as a historical recount and the English one as a personal recount.

The English text under analysis in this paper is an excerpt (the Orientation stage) from the full text - a high scoring creative writing piece from a final year high school student in New South Wales, Australia. It is essentially a narrative about a young woman's experience of her grandmother's death and is written about in MackenHorarik (2008). In her paper, Macken-Horarik explores the linguistic and rhetorical features that make this text so successful. These include a rendering of experience as both concrete and abstract (using elaboration but particularly lexical metaphor), an exploitation of the information structure to get the right emphasis, and a coherence which is organised around heading towards a goal, almost as if there is a punchline (see Macken-Horarik 2008 for more detail).

The history text is the synopsis of a monograph on the Chinese fishing industry in colonial (1800s) Australia. It is of the historical recount genre. This topic was chosen as it was the topic of one of the history journal articles analysed in Dreyfus and Bennett (2017), and the specific text chosen as it was a whole text of not exhaustive length (200 words)

These two different texts from different contexts were chosen in order to offer some comparison in terms of the similarities and differences of circumstantial meanings functioning in different texts and contexts, and how these are realised similarly and differently through discourse semantics and lexicogrammatical choices.

\section{Field}

We begin our analysis from the perspective of field, as it is the most intuitive (being related to our experience of the world) and has been the most relevant to previous understandings of circumstantial meanings as shown in Dreyfus and Jones (2008, 2011). Doran and Martin (forthcoming) have developed new parameters for aspects of field, building on (Martin's 1992) work. Where Martin (1992) had posited the concept of activity for describing dynamic aspects of field, construing field as an unfolding of events; and taxonomy for describing static relations between items, including classification (type) or composition (part/whole), Doran \& Martin add the dimension of property, for describing and organising potentially gradable qualities of items and activities. These different choices are shown in the system network in Figure 3.

Doran \& Martin argue that property can take many forms. These may involve:

(1) qualitative descriptions (e.g., Everest is tall, it is climbed slowly);

(2) being graded and potentially ordered into arrays in relation to other properties (Everest is the tallest mountain on earth); and

(3) spatio-temporal position (they trudged through the snow, Everest is in Asia, Everest's current height). 


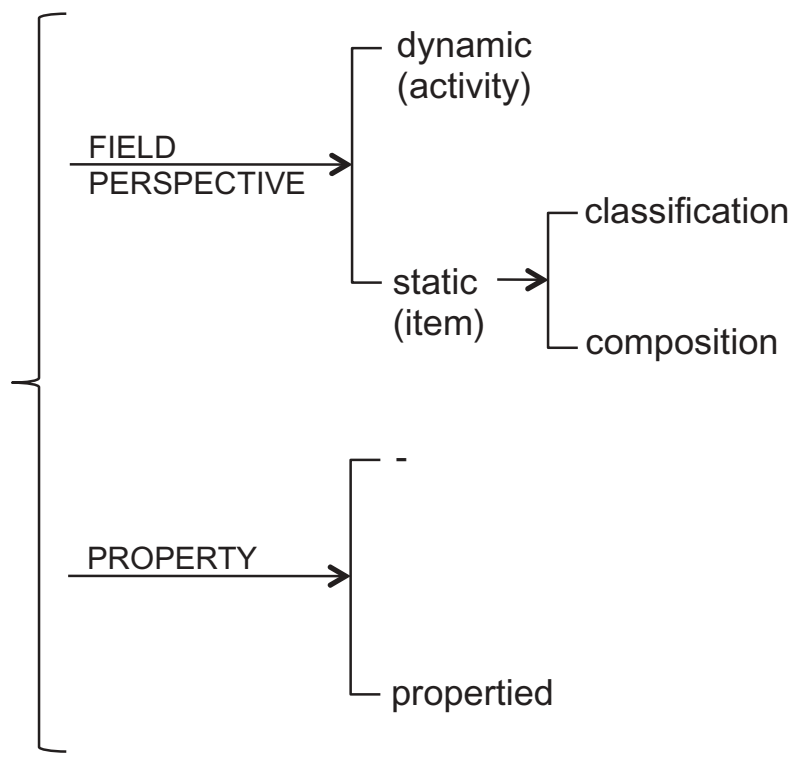

Figure 3. Field (Doran and Martin forthcoming).

Based on this description, the spatio-temporal position is of most relevance to the "circumstantial" meaning we are concerned with here, because it covers circumstantial meanings of space and time. Regarding lexicogrammatical realisations of Doran \& Martin's examples, in they trudged through the snow, through the snow is a Circumstance in a clause realising a spatial meaning; in the example Everest is in Asia, in Asia is an Attribute expressing a spatial meaning; and in the example Everest's current height, current is a Classifier expressing a temporal meaning. This recognition of spatio-temporal position as a category of field property resonates with previous concerns of circumstantial meanings being realised across a variety of grammatical constructions.

We adopt this spatio-temporal perspective as a first step because it means we do not have to limit ourselves to grammatical units, which was the initial problem identified in Dreyfus and Bennett (2017) - how to account for circumstantial meanings that occur in locations other than Circumstance in the clause. The spatiotemporal positions in (the Orientation of) the English text and on the whole history text are highlighted below, and then classified in a table identifying the lexicogrammatical structures that realise them:

Text 1. Spatio-temporal positions in the orientation stage of the English text.

In her last years my grandmother spent much of her time in an arm chair by the window of her room. The nursing home in which I visited her lay amidst a basin of green lawn and tidy, herbaceous borders, but it was at the towering blue gums that my grandmother stared, quiet and still. The constant, dull murmur of reassurance, tantrums, tears and bedpans eddied around her frail form, but she found resistance in those trees swaying leaves and dappled trunks in blue, purple and gold. They took her back, I think, to her real place, in the fields and dirt tracks of Tarren, country New South Wales. 
Text 2. Spatio-temporal positions in the history text.

\begin{abstract}
During the 1850s and 1860s, Chinese immigrants played a major role in the development of the fishing industries in Australia. Prior to their involvement, the industry was hampered by the problems posed by the transportation of fish to market. It was common for whole catches of fish to putrefy before they could reach their destination. The influx of Chinese gold miners, who relied on fish as a dietary staple, increased the demand that prompted the creation of many Chinese fish-curing establishments.

Chinese fish curers in colonial Australia fished but also purchased large quantities of fish, creating a new and reliable market for European fishermen. Fish-curing businesses supplied their compatriots on the goldfields with fresh and cured fish. These establishments, which made sums of money far greater than any European fishing operation, provided hundreds of jobs for both European and Chinese Australians in the fishing industry.

Very few pieces of documentary evidence, along with archaeological records from one colonial-period Chinese fishcuring camp in Victoria, remain. They reveal a fascinating story of how Chinese fish curers successfully dominated Australia's fishing industry; how they lived, worked, organised themselves, participated in colonial society, and the reasons why they suddenly disappeared.
\end{abstract}

This first step of analysis enables us to identify circumstantial meanings that occur anywhere in the lexicogrammar, because the focus is on spatio-temporal meaning, rather than on the lexicogrammatical constituent of Circumstance. However, since this first analysis relies heavily on the analyst's intuitions, it is sometimes difficult to determine whether an instance belongs to one category or another. For example, in the history text, it is questionable whether in the development of the fishing industries is a spatial or temporal property. Here we decide to draw on a grammatical probe, by asking in what did they play an important role?. It seems that spatial properties are able to be probed by "what", but temporal ones are usually not able to be probed in this way.

Text 1 shows that in the English text, spatial meanings predominate, with 9 of the 10 spatio-temporal positions being of the spatial type. These dominant spatial meanings help to provide a setting for the everyday life being described.

Text 2 shows that in the history text, there are slightly more temporal meanings (3 out of 11) than in the English text; however, spatial meanings still predominate (7 out of 11). There are both spatial and temporal meanings because, in history, both time and place are equally important in understanding historical events. Sometimes time and place are also conflated, as shown in examples like colonial Australia and colonial society, with colonial capturing the temporal aspect of the place.

\title{
4. Relationship between field and lexicogrammar
}

As a second step, we examine the grammatical resources that are involved in realising these temporal and spatial properties. In Tables 5 and 6 below, we map the grammatical choices to

Table 5. Spatio-temporal positions and their lexicogrammatical realisations in the English text.

\begin{tabular}{|c|c|c|}
\hline Spatio-temporal positions & $\begin{array}{l}\text { Lexicogrammatical } \\
\text { realisation }\end{array}$ & Type of position \\
\hline In her last years & Circumstance & temporal \\
\hline in an arm chair & Circumstance & spatial \\
\hline by the window of her room & Circumstance & spatial \\
\hline (The nursing home) in which I visited her & Qualifier & spatial \\
\hline amidst a basin of green lawn and tidy, herbaceous borders & Circumstance & spatial \\
\hline at the towering blue gums & $\begin{array}{l}\text { Attribute (Predicated } \\
\text { Theme) }\end{array}$ & spatial \\
\hline around her frail form & Circumstance & spatial \\
\hline in those trees' swaying leaves and dappled trunks in blue, purple and gold & Circumstance & spatial \\
\hline back ... to her real place & Circumstance & spatial \\
\hline (which is) in the fields and dirt tracks of Tarren, country New South Wales & Attribute & spatial \\
\hline
\end{tabular}


Table 6. Spatio-temporal positions and their lexicogrammatical realisations in the history text.

\begin{tabular}{lll}
\hline Spatio-temporal positions & Lexicogrammatical realisation & \multicolumn{1}{c}{ Type of property } \\
\hline During the 1850s and 1860s & Circumstance & temporal \\
in the development of the fishing industries & Circumstance & spatial \\
in Australia & Circumstance & spatial \\
Prior to their involvement & Circumstance & temporal \\
to market & Circumstance & spatial \\
before they could reach their destination & hypotactic clause & temporal \\
in colonial Australia & Qualifier & spatial (with temporal) \\
on the goldfields & Qualifier & spatial \\
in the fishing industry & Qualifier & spatial \\
from one colonial-period Chinese fish-curing camp in Victoria & Qualifier & spatial (with temporal) \\
in colonial society & Circumstance & spatial (with temporal) \\
\hline
\end{tabular}

the types of spatio-temporal relations. What is revealed by this is that each of the two texts favours somewhat different grammatical choices.

In Text 1, most of the spatial properties are realised grammatically through Circumstances (seven) at the clause rank, two are realised through Attributes and one through a Qualifier.

In comparison, Text 2 has more diverse grammatical choices. In addition to the typical choice of Circumstances (six), Text 2 also has a number of Qualifiers (three), and there is also one hypotactic clause. Given this text is a synopsis of an academic book about the colonial fishing industry, the presence of the Qualifiers signals the longer and more complex nominal groups that are typical of highly written language (Halliday 1985). The Qualifiers can be realised through a prepositional phrase involving a downranked nominal group, which, as Halliday $(1985,70)$ suggests, increases the lexical density of written language.

To recap our analysis so far, applying the concept of spatio-temporal position as a property in the field provides us with a way of relating circumstantial meaning at the contextual level to a range of choices at the grammatical level. The linking of meanings between these two strata is shown in Figure 4.

Figure 4 depicts the pressure that spatio-temporal property puts on the lexicogrammar, generating a diverse set of realisations of circumstantial meaning. However, this does not account for everything there is to know and understand about circumstantial meaning. This is clear if we examine the spatio-temporal properties in these two texts side by side. In doing this, we find that many in the English text are very specific and tangible, being people, places, and things in the everyday context, e.g., my grandmother, the armchair, the window, and her room. In contrast to this, while some of the spatio-temporal properties in the history text are also specific places and things, such as to market, others are more distant from the everyday context and refer to intangible ideas, e.g., the development fishing industries, their involvement, their destination. It is these differences that we now explore, as these kinds of meanings are important in revealing the differences between creative writing in subject English and recount writing in history, that is, helping to account for differences in both genre and register. In order to explore this, we deploy understandings from the discourse semantic system of ideation (after Hao 2015, forthcoming a, forthcoming b; c.f. Martin 1992).

\section{A discourse semantic perspective on "circumstantial" meanings"}

Moving to the level of discourse semantics, we can explore the kinds of meaning that configure in the co-text. Building on ideational discourse semantic meaning developed by 


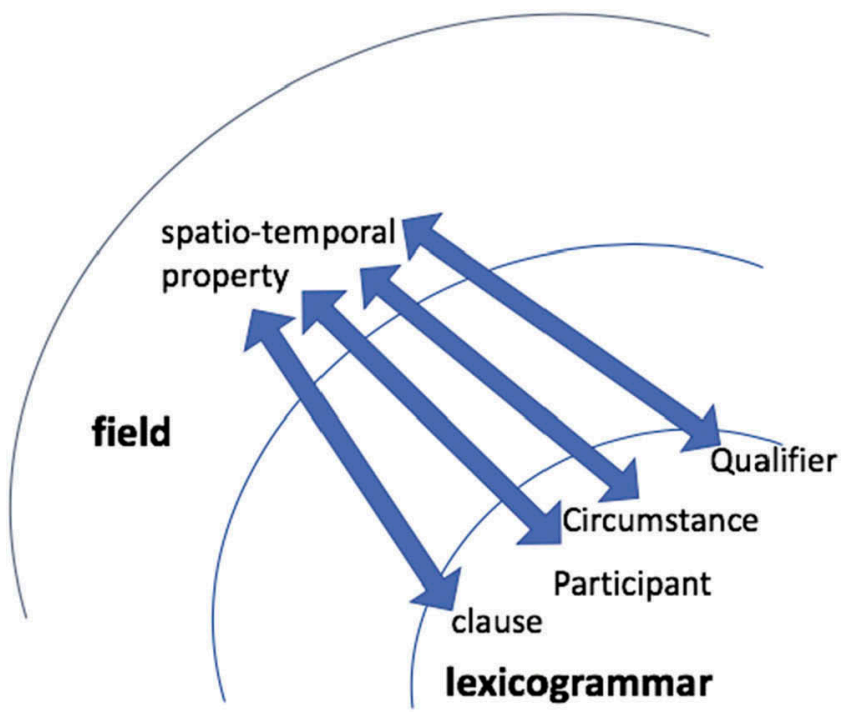

Figure 4. Spatio-temporal property realised as a variety of lexicogrammatical structures.

Martin (1992), Hao (2015) describes several discourse semantic meanings, including entities and their dimensions, qualities, occurrences, and figures (and their expansion into sequences). In this paper, we analyse the kind of discourse semantic meanings that are involved in the spatio-temporal instances identified from the perspective of field. We will introduce these units one by one and show that all these discourse semantic units are relevant to construing the "spatio-temporal" properties, and thus contribute to a fuller understanding of "circumstantial meaning".

\section{Entities}

Entities build lexical cohesion in a text, as they are the "things" in a text that we can track. Moving up to register, and looking from the perspective of field, entities can construe items; and finally, looking from below, they are realised through the nominal group constituent of Thing, with a potential elaborated structure of Classifier^Thing, as presented in Table 7.

Hao (2015, forthcoming a) classifies entities into a number of types, including:

- thing entities, which typically refer to tangible and observable items, such as chair, window, room;

- activity entities, which name a series of chronologically (and logically) sequenced and unfolding activities in the field, such as the fishing industry; Activity entities

Table 7. Entity.

\begin{tabular}{ll}
\hline Field & \multicolumn{1}{c}{ Item } \\
\hline Discourse semantics & entity \\
typical lexicogrammatical realisation & $\left(\right.$ Classifier $\left.^{\mathrm{n}} \wedge\right)$ Thing \\
example & colonial Australia; fishing industry \\
\hline
\end{tabular}


enable field activities to be construed statically, in other words, from a grammatical perspective, they "collapse" whole clauses down to nominal elements;

- semiotic entities, which name semiotic resources, such as words, texts, images;

- time entities. Following Bennett (2016) distinctions can be made along a point of time (e.g., $10 \mathrm{am}$ ), a duration of time (e.g., the 1850s and 1860s) and open-ended time (e.g., the future)

- place entities, which provide resources for the naming of places, such as New South Wales, Australia; and

- people entities, which refer to the roles and titles of people such as my grandmother, or their collective groups such as community, assembly, etc.

In discourse, entities interact in complex ways with textual references, which means that very often entities are identified and tracked textually and can be made elliptical. In order to conduct a thorough entity analysis, we need to recover all entities, so this means we must backfill all ellipsis and reference items. For example, in the instance before they could reach their destination, the textual reference they can be recovered as the fish.

An entity analysis of the spatio-temporal properties in the Orientation to the English text reveals that there are three types of entity: time, place, and thing, with different numbers of each type. There are:

- one time entity: her last years;

- four place entities: nursing home, (her real) place, Tarren, country New South Wales; and

- eleven thing entities: armchair, the window, her room, green lawn, herbaceous borders, blue gums, trees, swaying leaves, dappled trunks, fields, and dirt tracks.

The time entity In her last years, begins the whole text, temporally locating the story at the end of the grandmother's life. The three place entities serve to ground the writer's musings of her grandmother feeling more at home in the place where she grew up. But it is the eleven thing entities that ground the story in the everyday world of the nursing home and its surroundings. The wide range of thing entities helps to set the scene through the spatio-temporal properties in this story.

In contrast to this, the entity analysis of the spatio-temporal properties in the history text reveals there are four types of entity: time, thing, activity, and place, in the following numbers:

- two time entities: the 1850s and 1860s and colonial period;

- one thing entity: they (referring to fish);

- one people entity (as a collective group): colonial society;

- two activity entities: The fishing industry and fishing industries; and

- seven place entities: Australia, market, their destination, colonial Australia, the goldfields, Chinese fish curing camp and Victoria.

The time entities locate the events in their time period - which is a feature of history texts (see Coffin, 2006). The thing entity fish refers to an important item involved in the fishing industry. There is one people entity, referring to the collective group colonial 
society, rather than an individual historical figure. The activity entities are about the fishing industry, and this encompasses all the activities involved in the fishing industry, such as the preparation, catching, curing, transporting, and selling of fish. This activity entity enables all these actions to be compressed into one abstract nominal group which can then be talked about as a thing in the text. At the same time, the use of activity entities assumes in readers a great deal of specialised field knowledge.

Of the most significance in this history text are the seven place entities. This corresponds with our field analysis, where it was shown that both spatial and temporal properties are important. From a discourse semantic perspective, the significance of places can be reflected in two ways. First, these places are co-related taxonomically in terms of their geographic locations, as shown in Figure 5. Victoria is a part of Australia and the three other places are parts of Victoria.

Given this text is talking about a fishing industry, where each of the groups of actions occurs is significant - catching and curing in Victoria and being taken to market and the goldfields to be sold. The place entities are an important part of the experiential meaning in sequencing the activities.

A second important feature of the place entities in this text is the way in which places are classified based on a time period - colonial Australia. This reveals that place is not just a geographic location, but its location in time is a distinguishing feature of historical knowledge. The taxonomy in Figure 5 would be different if contemporary Australia was a place entity at stake.

\section{Dimensions of entity}

The analysis of entities can be expanded further by taking into account their dimensions. Dimensions augment and are dependent on entities, even if sometimes the entity may be elided and needs to be recovered textually. Several types of dimensions are identified, in terms of how entities are categorised (e.g., a type of ...), structured (the shape of ...), measured (e.g., a cup of ...) and perceived (e.g., the taste/texture/flavour of ...). Grammatically, dimensions are realised prototypically through a Focus group in the nominal group, e.g., a kind of tree. However, this grammatical structure can be rendered in many other ways, such as Classifier^Thing (tree types), Possessive Deictic^^Thing (trees' types), or a Thing when the entity is elliptical (types). Since entities construe items that can be taxonomically related in building a field, dimensions of entities make explicit the taxonomic relations in the discourse, and also

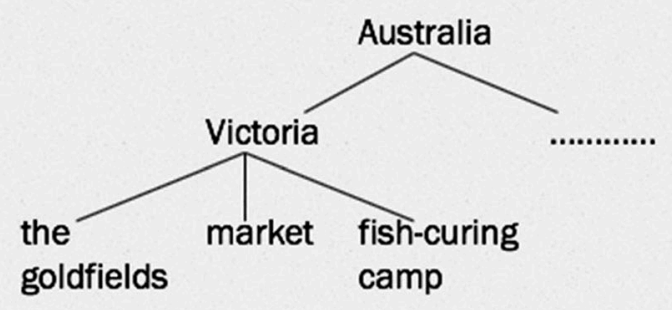

Figure 5. Part-whole relationship between entities of place. 


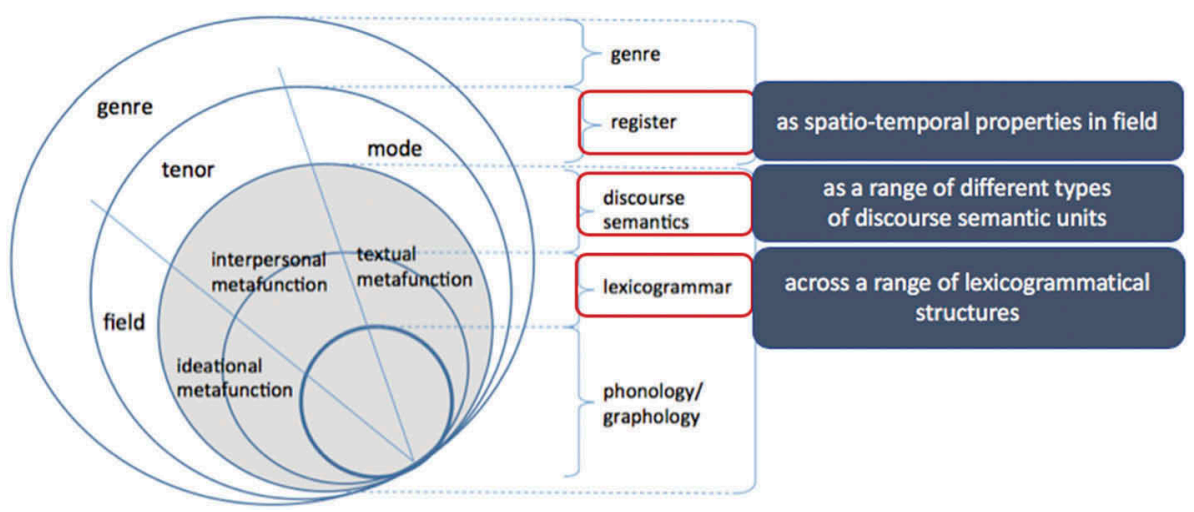

Figure 6. Realisations of circumstantial meanings across three strata.

Table 8. Dimensions of entity.

\begin{tabular}{ll}
\hline Field & Taxonomic relations; qualitative properties \\
\hline Discourse semantics & dimensions of entity \\
typical lexicogrammatical realisation & in Focus group; \\
& Thing in nominal group \\
example & $\begin{array}{l}\text { a kind of tree } \\
\text { type, shape, length }\end{array}$ \\
\hline
\end{tabular}

name the qualitative properties of items that are the distinguishing criteria of taxonomic relations. Table 8 shows the dimensions of entities and their corresponding realisations at higher and lower strata.

There are two dimensions in the spatio-temporal properties in the English text: a basin of green lawn and her frail form (where form refers to the form of her body). These dimensions function to provide further description in this text by describing the way things are shaped - indicating the visual nature of the spatial setting being construed in this story. These dimensions serve to make the setting more vivid for the reader - perhaps forming part of the craft of good creative writing.

In contrast, the history text has no instances of dimension in its spatio-temporal properties. Interestingly, although through our entity analysis, taxonomic relations of places were revealed, such as Victoria being part of Australia, no explicit naming through dimensions was found. That is to say, there were no explicit dimensions augmenting these entities, such as the state of Victoria. This suggests that while places play an important circumstantial role, explicit construction of their taxonomies is not a significant concern in this text. This would contrast with, for example, the importance of dimensions in naming taxonomic relations of places in a geography text (e.g., states of Australia; continents of the world, etc.).

\section{Quality}

The third relevant element of discourse semantics that we need for our description of the spatio-temporal properties in these two texts is quality. Quality extends entities and is realised typically through Epithets or Attributes in the lexicogrammar, typically realised by the word class of adjective, e.g., green lawn (see Table 9 below). 
Table 9. Quality.

\begin{tabular}{ll}
\hline Field & Type of property \\
\hline Discourse semantics & quality \\
typical lexicogrammatical realisation & Epithets or Attributes \\
example & green lawn; \\
& the lawn is green \\
\hline
\end{tabular}

Although discourse semantic qualities are a typical realisation of qualitative properties at the level of field, we found that they also play an important role in describing spatiotemporal properties. There are nine qualities in the spatio-temporal properties in the English text, being concerned as it is with describing people, places, and things. These include: a basin of green lawn, tidy herbaceous borders, towering blue gums, her frail form and dappled trunks in blue, purple and gold. Of note here is that almost all the thing entities construing the spatial properties are coupled with a quality. These qualities, seeing from an interpersonal perspective within discourse semantics, couple attitudinal meanings within entities (see appraisal system in Martin and White 2005), serving to build vivid descriptions which resonate and provoke "feelings" in the reader towards the spatial scene. The more detailed the entities and qualities are, the more we are able to resonate with the text and align our "feelings" with the spatial scene in the story, and with the story overall.

Interestingly, the history text does not have any qualities construing the spatio-temporal property of the historical events. That is to say, there is little description or evaluation of the places where the historical events take place. However, this is certainly not to say that no attitudinal meaning is made in other ways in the text. In fact, many qualities combine with entities, but these do not construe the qualitative properties of items within the spatiotemporal meaning, rather they construe other types of meanings. For example, the entity Chinese immigrants are explicitly evaluated with a positive attitudinal resource in Chinese immigrants played a major role.

Overall, these two texts reveal how qualities can play interesting contrasting roles - in the English text, the role of the qualities is to depict the "ambience" of space around a person, which is an important feature of a successful literary text; in the history text, the role of quality is to evaluate the people who are at the centre of the historical development.

\section{Figure}

A figure is a configuration of discourse semantic elements (entity, occurrence, quality) typically realised through a clause. Hao (2015) distinguishes a number of figure types based on different discourse semantic configurations. Primarily, a configuration of occurrence (typically realised through a Process) with one or more entities is known as occurrence figure, construing dynamic activities in a field (e.g., she walked into the room). Occurrence figures are typically realised by material and behavioural clauses. A figure configuration without an occurrence is known as a state figure, and can be either constituted by an entity and a quality, construing qualitative properties of an item (e.g., the room is big), or constituted by only entities construing taxonomic relations (e.g., Victoria is a state of Australia). State figures are typically realised through relational clauses.

A figure can be expanded by relating to another figure through a logical connexion (e.g. She entered the room and then the phone rang). Connexion is typically realised 
through conjunctions. Logically connected figures are referred to as sequences and can construe a series of activities in the field, or they can make connections between phenomena from different realms of the experiential world. A sequence of figures is typically realised through an expanded clause complex.

It is not always easy to recognise figures and sequences in discourse because they can be mapped metaphorically onto the grammar. That is to say, while figures can be mapped congruently onto a clause (e.g., she entered the room), they can also be mapped metaphorically onto a group (e.g., her entering the room). By realising a figure through a group, a sequence can then be realised metaphorically through a clause (e.g., her entering in the room was followed by the ringing of the phone) (Martin 2008; Hao 2018). Table 10 presents both congruent and metaphorical realisations of figures

The figure analysis in the spatio-temporal properties of our two texts shows that occurrence figures are of significance in construing activity in the history text, but not in the English text. Amongst the three occurrence figures identified in the history text, two are realised metaphorically by remapping a figure to a nominal group as part of a Circumstance, e.g., in the development of the fishing industries (i.e., when the fishing industries were developed) and prior to their involvement (i.e., before Chinese immigrants were involved in the fishing industry). One occurrence figure is realised congruently through a hypotactic clause - before they could reach their destination. These occurrence figures demonstrate that a function of spatio-temporal property in the history text concerns temporally relating certain activities to other activities.

By contrast, only one occurrence figure was found in the English text. In this instance, a figure is realised through a downranked clause - i.e., (The nursing home) in which [[I visited her]]. The figure I visited her functions to modify the place rather than connect it logically with another figure.

Tables 11 and 12 show all the spatio-temporal properties in both texts from the perspective of discourse semantics:

Table 10. Figure.

\begin{tabular}{lll}
\hline Field & \multicolumn{2}{c}{ Activity } \\
\hline Discourse semantics & figure & \\
lexicogrammatical realisation & $\begin{array}{l}\text { congruent: clause } \\
\text { example }\end{array}$ & metaphorical: group \\
& & her entering the room \\
\hline
\end{tabular}

Table 11. Discourse semantic realisations in spatio-temporal properties in the English text.

\begin{tabular}{|c|c|}
\hline English text & Discourse semantics \\
\hline $\begin{array}{l}\text { In her last years } \\
\text { in an arm chair } \\
\text { by the window } \\
\text { (The nursing home) in room } \\
\text { amidst basin of green lawn and tidy, herbaceous borders } \\
\text { at the towering blue gums } \\
\text { around her frail form (of her body) } \\
\text { in those trees' [[swaying]] leaves and dappled trunks in blue, purple and gold } \\
\text { back... to her real place } \\
\text { in the fields and dirt tracks of Tarren, country New South Wales }\end{array}$ & $\begin{array}{l}\text { entity [time] } \\
\text { entity [thing] } \\
\text { entity [thing } \times 2 \text { ] } \\
\text { entity [place] } \\
\text { occurrence figure } \\
\text { dimension } x 2>\text { thing } \\
\text { entity [thing] } \\
\text { dimension }>\text { Thing } \\
\text { entity [thing] } \times 3 \\
\text { entity [place] } \\
\text { entity [thing] } \times 2 \text {, } \\
\text { entity [place] }\end{array}$ \\
\hline
\end{tabular}


Table 12. Discourse semantic realisations in spatio-temporal properties in the history text.

\begin{tabular}{ll}
\hline History & Discourse semantics \\
\hline $\begin{array}{l}\text { During the 1850s and 1860s } \\
\text { in the development of the fishing industries }\end{array}$ & entity [time] \\
\cline { 2 - 2 } in Australia & $\begin{array}{l}\text { occurrence figure; } \\
\text { activity entity }\end{array}$ \\
to market & entity [place] \\
Prior to their involvement, & entity [place] \\
before they (fish) could reach their destination & occurrence figure \\
\cline { 2 - 2 } & occurrence figure; \\
in colonial Australia & entity [thing] \\
on the goldfields & entity [place] \\
in the fishing industry & entity [place] \\
from one colonial-period Chinese fish-curing camp in Victoria & entity [place] \\
& activity entity \\
in colonial society & entity [time] \\
\hline
\end{tabular}

Table 13. Numbers of different discourse semantic meanings in the two texts.

\begin{tabular}{lcc}
\hline & English text & History text \\
\hline thing entity & 11 & 1 \\
activity entity & 0 & 2 \\
time entity & 1 & 2 \\
place entity & 4 & 7 \\
people entity & 0 & 1 \\
occurrence figure & 1 & 3 \\
dimension & 3 & 0 \\
quality & 9 & 0 \\
\hline
\end{tabular}

In summary, and as per Table 13, in the English text, thing entities and qualities predominate, showing the significance of providing descriptions of a space/place, which fulfils the descriptive nature of this literary text. By contrast, in the history text, place entities are the most frequent, but these are not further described by qualities. The use of occurrence figures to build temporal sequences of activities is a more significant feature than in the English text.

\section{Conclusion}

In summary, we have shown that the diverse range of circumstantial meanings at the grammatical level, which include Circumstances, Participants at the clause rank, Qualifiers at the group rank, and hypotactic clauses in a clause complex, can make rich circumstantial meanings at "higher" levels. From the perspective of field, we can see that these grammatical realisations construe spatio-temporal properties of the field instantiated in the text. However, it is the discourse semantic analysis that reveals the diversity of how spatio-temporal properties can be construed through language.

There are two significant conclusions to be drawn from this multi-stratal exploration of circumstantial meanings: first, understanding how the meanings are construed cannot be solved from the perspective of lexicogrammar alone. Considering a question from all three 
strata allows us to have an integrated view of how language is used in relation to its context. The lexicogrammatical stratum can account for the realisations of circumstantial meanings in their lexicogrammatical structures; the register stratum can account for all these meanings, no matter which lexicogrammatical structure realises them, in terms of the kind of item they construe in field - as a spatio-temporal property; and the discourse semantics stratum can account for them in terms of what exactly is going on inside each meaning: what types of entities, etc., construe these spatio-temporal properties in the field.

The second conclusion to be drawn from this "multi-stratal" analysis the way this analysis is able to make visible the significant differences in the circumstantial meanings in two different genres and registers. In the student's high scoring creative writing text, circumstantial meanings play an important role in building the "ambience" of the place around the character in the narrative. Through naming specific things and describing them with qualities, the text depicts a vivid visual image of what the narrative setting "looks like" and "feels like", contributing to the creation of particular worlds of meaning that we are familiar with in creative writing. This is a successful literacy strategy which serves to align the readers to "feel" the place in the narrative setting, to be able to clearly imagine it. By contrast, the circumstantial meanings in the history text locate the historical events in a particular time and place. The places are taxonomically related, and places are classified by time. The spatio-temporal properties function as factual information that build the knowledge of these historical events.

Although from a grammatical perspective "circumstantial meaning" tends to be treated as something "peripheral" and often misconceptualised as being "extra", our analyses of two sample texts have shown that these, in fact, play an important role in building a text and its corresponding context (genre and register). The multi-stratal meaning potential of "circumstantiation" needs to be explored further by examining more diverse registers and genres in future studies.

\section{Note}

1. Following SFL convention, this paper uses initial capitals to indicate functional units - i.e., Process, Participants, and Circumstances are functional units in a clause; and small caps are used to indicate names of systems - e.g., transitivity, ideation, appraisal.

\section{Disclosure statement}

No potential conflict of interest was reported by the authors.

\section{Notes on contributors}

Shoshana Dreyfus is Senior Lecturer in English Language and Linguistics at the University of Wollongong, Australia. She specialises in SFL, discourse analysis and 'Sydney School' Genre Pedagogy, with a focus on academic literacy, language disorder, circumstantial meaning, evaluative language and other sorts of meaning making.

Dr Jing Hao is currently a Postdoctoral Researcher Fellow at the Pontificia Universidad Católica de Chile, following her previous postdoctoral position fellowship at The Hong Kong Polytechnic University, and her doctorate in Linguistics at the University of Sydney. Her research explores 
knowledge building through English and Mandarin Chinese and their its interaction with other semiotic modes.

\section{ORCID}

Shoshana Dreyfus (iD) http://orcid.org/0000-0002-0592-9279

\section{References}

Bennett, I. 2016. "Contextual Meanings: An Investigation of Their Persuasive Power in Research Article Introductions." Unpublished Master of Arts (Research) Thesis, University of Sydney.

Coffin, C. 2006. Historical Discourse: The Language of Time, Cause and Evaluation. London: Continuum Doran, Y. J., and J. R. Martin. forthcoming. "Field Relations: Understanding Scientific Explanations." In Studying Science: Knowledge, Language and Pedagogy, edited by K. Maton, J. R. Martin, and Y. J. Doran. London: Routledge.

Dreyfus, S., and P. Jones. 2011. "Mapping Place: Further Delicacy in Circumstantiation." In Explorations in the Theory and Application of Systemic Functional Linguistics, edited by F. Yan, 70-94. Beijing: Higher Education Press of China.

Dreyfus, S., and I. Bennett. 2017. "Circumstantiation: Taking a Broader Look at Circumstantial Meaning." Functional Linguistics 4 (5): 1-31. Springer Open.

Dreyfus, S., and P. Jones. 2008. "Making Sense of Place: Further Descriptions of Circumstance of Location." Voices from around the world conference proceedings, Sydney: Macquarie University, July 2008.

Halliday, M. A. K. 1985. An Introduction to Functional Grammar. London: Edward Arnold.

Halliday, M. A. K., and C. M. I. M. Matthiessen. 2014. Halliday's Introduction to Functional Grammar. London and New York: Routledge.

Hao, J. 2015. "Construing Biology: An Ideational Perspective." Unpublished PhD Thesis, University of Sydney.

Hao, J. 2018. "Reconsidering "Cause inside the Clause" in Scientific Discourse - From a Discourse Semantic Perspective in Systemic Functional Linguistics." Text \& Talk 38 (5): 520-550.

Hao, J. 2020a. "Building Taxonomy in Undergraduate Biology. To Appear." In Studying Science: New Insights into Knowledge and Language in Education, edited by K. Maton, J. R. Martin, and Y. J. Doran. London and New York: Routledge.

Hao, J. 2020b. "Nominalisations in Scientific English: A Tristratal Perspective." Functions of Language. John Benjamins.

Macken-Horarik, M. 2008. "Multiliteracies and 'Basic Skills' Accountability." In New Literacies and the English Curriculum, edited by L. Unsworth, 283-508. Bloomsbury: London.

Martin, J. R. 1992. English Text: System and Structure. Amsterdam: Benjamins.

Martin, J. R. 1997. "Analysing Genre: Functional Parameters." In Genre and Institutions: Social Processes in the Workplace and School, edited by F. Christie and J. R. Martin, 3-39. London: Cassell.

Martin, J. R. 2008. "Incongruent and Proud: De-vilifying 'Nominalization'." Discourse \& Society 19 (6): 801-810.

Martin, J. R. this volume. "Metaphors We Feel By: Stratal Tension." Journal of World Languages.

Martin, J. R., and P. R. R. White. 2005. The Language of Evaluation: Appraisal in English. London: Palgrave.

Matthiessen, C. M. I. M. 1998. "The Transitivity of Space in Topographical Procedures." Unpublished Draft. 


\section{Appendix}

English text:

In her last years my grandmother spent much of her time in an arm chair by the window of her room. The nursing home in which I visited her lay amidst a basin of green lawn and tidy, herbaceous borders, but it was at the towering blue gums that my grandmother stared, quiet and still. The constant, dull murmur of reassurance, tantrums, tears and bedpans eddied around her frail form, but she found resistance in those trees' swaying leaves and dappled trunks in blue, purple and gold. They took her back, I think, to her real place, in the fields and dirt tracks of Tarren, country New South Wales.

And so, when she died, that is where I took her. My grandfather, who died years before, had bought a double gravesite for them both in the cemetery near our home, and had extracted a promise that they would lie there together with one tombstone. His name came first.

The nursing home lot were a modern liberal-minded group. The advocated cremation, cremation and sprinkling "on your own special place". With a gleam in her eye my grandmother voiced her wish to be incinerated and scattered. One in the eye to her husband (Godrest his soul) who always got his way, and his name, before her own.

She died in March of 2000, and while the family clucked and muttered, and her lawyer stood firm, I made the arrangements. Two days after the funeral I set out in the family sedan for my grandmother's country, unseen and anticipated, with the urn on the seat beside me.

In a fit of whimsy, I found the country and western station, wound down the windows and hurtled down the highway, alternatively signing, crying and talking to my dead grandmother.

I didn't really believe she was listening. I hoped she had better things to do.

We soon tired of the country station and the speeding. Too blokey, perhaps, for us girls.

I fiddled idly with the tuner and found the ABC Classic station. Violins, flutes and tinkling bells and Baroque precision filled the car, and as we drove, I began to let my eyes stray from the road.

The sun was bright, and dry heat sat heavily on the fields by the highway. Weeds and thickets of grass, beyond bovine reach, obscured much of the fences and the tidy lines of one-eyed soldiers. Beacons of red reflection for those drivers in the dark, I thought. I am in the dark, I thought.

Sun slanted through the window across my bare arms, picking out the fine golden hairs there. They looked like billowing fields of uncut tan coloured grass, undulating in waves like the ocean. I liked that. I imagined myself, my body as a miniature landscape - roughness and smooth, cracked, dry with rivers of sweat and unreliable fountains of tears.

The music changed. Something romantic swelling and disappearing suddenly with vibrating emotion. European music. So odd that at that precise moment, on that precise day, it captured my surroundings like a map. I had moved from the rolling fields into state forest, imposing and beginning to buzz with late afternoon cicadas. The lickering of golden light through the trees painted the forest floor with gold, pin pointed by charred remains of broken trees. Light and shadow. Sight and blackness. Louds and softs. The dynamics of this landscape so intimately connected with my own.

Time for the map (sadly only of outward geography). The turn off for Tarren gorge was surely approaching.

As I swerved the car gently off the highway onto the gravel crescent, the stones leapt up in welcome, tapping at my door. They crunched beneath my feet as I climbed from my seat, urn in hand, and set off through the narrow track through the trees. Forgotten bark chiping lay beneath a layer of forest refuse, mulching quietly in the fading sun. My cramped legs tired easily and I distracted myself with the bark of the trees I passed - here rough, there smooth, there traced with the tracks of tiny boring insects.

My step lightened as I came out from the eucalyptus canopy onto the escarpment. Here there was wind, and the sun was gone. I paced the edge, stealing glances down into the water snaking below. Not as deep as I expected ... the tall tales of my father debunked, but I would not be the one to tell.

Minutes passed, but they not felt in that place. Dimly, trucks could be heard on the highway, but it might have been the dull roar of flooding waters. The private memories of that gorge ... merge them with my own.

With no one else to see but the trees and the earth, my grandmother was scattered out into the air, and floated downwards to the rocks and the water. I lost sight of her quickly. I felt no better, or worse, 
but I was secretly glad to have done this, and alone. A private moment of connection in detachment. No words or prayers. Not even thoughts. I felt like the land around me, because alone in my grandmother's county, I just was.

\section{History text:}

During the 1850s and 1860s, Chinese immigrants played a major role in the development of the fishing industries in Australia. Prior to their involvement, the industry was hampered by the problems posed by the transportation of fish to market. It was common for whole catches of fish to putrefy before they could reach their destination. The influx of Chinese gold miners, who relied on fish as a dietary staple, increased the demand that prompted the creation of many Chinese fish-curing establishments.

Chinese fish curers in colonial Australia fished but also purchased large quantities of fish, creating a new and reliable market for European fishermen. Fish-curing businesses supplied their compatriots on the goldfields with fresh and cured fish. These establishments, which made sums of money far greater than any European fishing operation, provided hundreds of jobs for both European and Chinese Australians in the fishing industry.

Very few pieces of documentary evidence, along with archaeological records from one colonialperiod Chinese fish-curing camp in Victoria, remain. They reveal a fascinating story of how Chinese fish curers successfully dominated Australia's fishing industry; how they lived, worked, organised themselves, participated in colonial society, and the reasons why they suddenly disappeared. 